\title{
Leukemia cutis preceding systemic relapse of acute myeloid leukemia
}

\author{
M. Stern · J. Halter · A. Buser · A. Rovò • \\ S. Dirnhofer · P. Häusermann
}

Received: 22 November 2007/Revised: 12 January 2008/ Accepted: 6 February 2008/Published online: 28 February 2008

(C) The Japanese Society of Hematology 2008
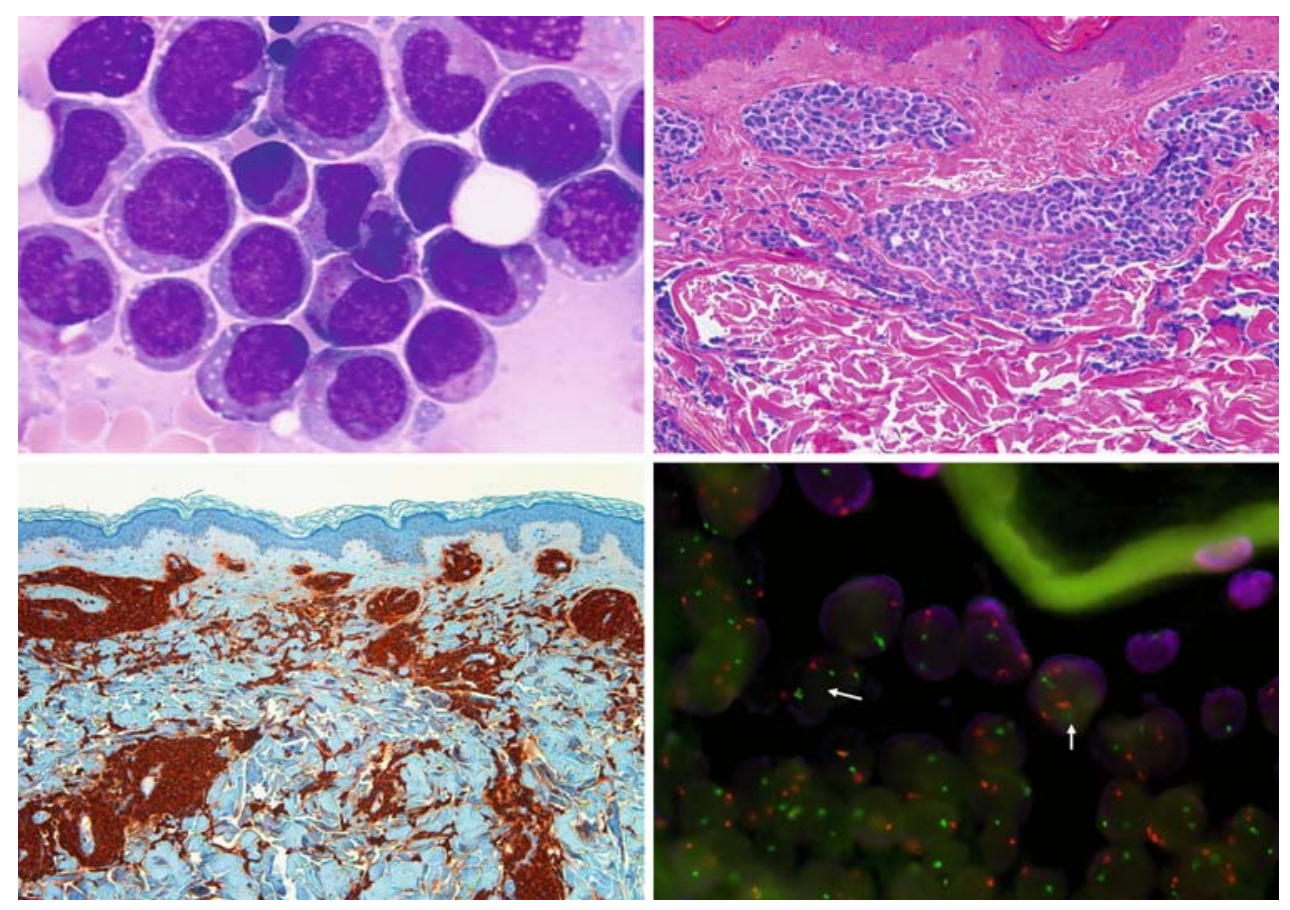

M. Stern $(\bowtie) \cdot$ J. Halter · A. Buser · A. Rovò

Department of Hematology, University Hospital,

$\mathrm{CH}$-Basel, Switzerland

e-mail: sternm@uhbs.ch

\section{S. Dirnhofer}

Department of Pathology, University Hospital,

CH-Basel, Switzerland

\section{P. Häusermann}

Department of Dermatology, University Hospital,

CH-Basel, Switzerland

A 27-year old male patient was diagnosed with acute myeloid leukemia without recurrent cytogenetic abnormalities, morphologically AML with maturation (FAB M2, upper left panel). Cytogenetic analysis revealed a near-tetraploid karyotype $(85, \mathrm{XXYY})$ with numerous structural abnormalities. Induction therapy was started with cytarabine and idarubicine. Bone marrow examination on day 17 showed persistence of leukemia, a reinduction with cytarabine was therefore administered. Bone marrow examination on day 17 of reinduction showed a leukemia-free state. Autologous 
hematopoetic stem cells were mobilized with G-CSF and collected. Shortly before treatment with G-CSF, the patient developed multiple papules on his trunk and head which exacerbated under treatment with G-CSF. After successful apheresis, one of the papules was biopsied. Haematoxylin/ eosin staining revealed a perivascular and periadnexal cutaneous infiltrate of highly atypical blastoid cells with characteristic "layering" around vessels and adnexal structures, and linear arrangement of neoplastic cells between collagen bundles ("indian filing") sparing the upper papillary dermis (upper right panel). As leukemic blast cells had not expressed CD34 at initial diagnosis, the diagnosis of leukemia cutis was confirmed by staining for myeloperoxidase (bottom left) and by fluorescent in-situ hybridization for centromers of chromosomes 6 (red) and 17 (green) revealing a hyper diploid karyotype in a majority of cells (i.e. more than four signals per nucleus, examples indicated by arrows, bottom right). Nine days after the biopsy, systemic relapse was diagnosed in blood and bone marrow. Reinduction treatment was administered and the patient awaits allogeneic stem cell transplantation. 